\title{
Long and Short Multifunicular Projections of Sacral Neurons Are Activated by Sensory Input to Produce Locomotor Activity in the Absence of Supraspinal Control
}

\author{
Alex Etlin, Dvir Blivis, Moriel Ben-Zwi, and Aharon Lev-Tov \\ Department of Medical Neurobiology, Institute for Medical Research Israel-Canada, The Hebrew University-Hadassah Medical School, Jerusalem 91010, Israel
}

\begin{abstract}
Afferent input from load and joint receptors has been shown to reactivate the central pattern generators for locomotion (CPGs) in spinal cord injury patients and thereby improve their motor function and mobility. Elucidation of the pathways interposed between the afferents and CPGs is critical for the determination of the capacity of sensory input to activate the CPGs when the continuity of the white matter tracts is impaired following spinal cord injury. Using electrophysiological recordings, confocal imaging studies of spinal neurons and surgical manipulations of the white matter, we show that the capacity of sacrocaudal afferent (SCA) input to produce locomotor activity in isolated rat spinal cords depends not only on long ascending pathways, but also on recruitment of sacral proprioneurons interposed between the second order neurons and the hindlimb CPGs. We argue that large heterogeneous populations of second-order and proprioneurons whose crossed and uncrossed axons project rostrally through the ventral, ventrolateral/lateral and dorsolateral white matter funiculi contribute to the generation of the rhythm by the stimulated sacrocaudal input. The complex organization and multiple projection patterns of these populations enable the sacrocaudal afferent input to activate the CPGs even if the white matter pathways are severely damaged. Further studies are required to clarify the mechanisms involved in SCA-induced locomotor activity and assess its potential use for the rescue of lost motor functions after spinal cord injury.
\end{abstract}

\section{Introduction}

Interaction of afferent input from joint and load receptors with spinal central pattern generators (CPGs) has been shown to play a major role in the ability of spinalized mammals to execute hindlimb treadmill stepping (Rossignol et al., 2006; Edgerton et al., 2008; Lavrov et al., 2008) and to control the timing and pattern of stepping (Pearson, 2004). Recent clinical studies have shown that reactivation of the CPGs in spinal cord injury patients by afferent input is possible, and that it improves the motor function and mobility of patients with incomplete thoracic spinal injury (Wernig et al., 1995; Colombo et al., 2001; Dietz et al., 2002; Dietz and Harkema, 2004; Dietz, 2009). Our findings that stimulation of sacrocaudal afferents (SCAs) in the isolated spinal cord of the neonatal rat is a potent activator of the pattern generating circuitry in the sacral and limb moving segments (Lev-Tov et al., 2000; Delvolvé et al., 2001; Strauss and Lev-Tov, 2003; Gabbay and Lev-Tov, 2004; Blivis et al., 2007; also see Whelan et al., 2000, for the neonatal mouse) enable us to use this preparation to study the functional organization and mechanism of action of the path-

Received March 9, 2010; revised June 3, 2010; accepted June 7, 2010.

This work was supported by The Israel Science Foundation Grants 129/04, 1591/08, and 1930/08, and by The US-Israel Binational Science Foundation Grants 2001010 and 2005020, to A.L.-T. Wethank Dr. G.Z. Mentisfor his advice and expertise in performance of the retrograde labeling experiments and Dr. M. J. $0^{\prime}$ Donovan for helpful comments on the manuscript.

Correspondence should be addressed to Dr. Aharon Lev-Tov, Department of Medical Neurobiology, Institute for Medical Research Israel-Canada, The Hebrew University Medical School, Jerusalem 91010, Israel. E-mail: aharonl@ekmd.huji.ac.il.

D. Blivis' current address: Section of Developmental Neurobiology, National Institute of Neurological Disorders and Stroke, National Institutes of Health, Bethesda MD 20892.

DOI:10.1523/JNEUROSCI.1208-10.2010

Copyright $\odot 2010$ the authors $\quad 0270-6474 / 10 / 3010324-13 \$ 15.00 / 0$ ways that are involved in sensory-activation of the CPGs, under controlled in vitro conditions. Our previous work revealed that the SCA-induced rhythm is not generated by direct contacts between the stimulated afferents and the hindlimb CPGs, but that it involves synaptic activation of sacral neurons whose axons project to the hindlimb innervating segments of the spinal cord through the white matter funiculi (Strauss and Lev-Tov, 2003; Lev-Tov and O'Donovan, 2009; Lev-Tov et al., 2010). We found that the rhythm could be blocked following application of the non-NMDA receptor antagonist CNQX, but not of the NMDA receptor blocker APV, to the sacral segments (Strauss and Lev-Tov, 2003), and following selective application of the $\mu$ opioid DAMGO to the sacral but not the lumbar segments of the spinal cord (Blivis et al., 2007). Currently, our understanding of the relative significance of pathways projecting through the known divisions of the white matter funiculi to the rhythm produced by SCA stimulation is rather limited and nonsystematic. Moreover, it is not known whether the sensory-induced rhythm depends on activation of sacral neurons with long ascending projections to the CPGs or if recruitment of groups of proprioneurons by second order sacral neurons is sufficient to activate the hindlimb CPGs. These issues are critical for determining the capacity of sensory input to activate the CPGs when the continuity of the ascending pathways is impaired by spinal cord injury. Therefore, understanding of the functional organization of the pathways that mediate that activation of the CPGs by SCA stimulation and clarification of their mechanisms of action are the main aims of the present study. Parts of our results have been described in an abstract (Etlin et al., 2009) and in 2 book chapters (Lev-Tov and O'Donovan, 2009; Lev-Tov et al., 2010). 
A

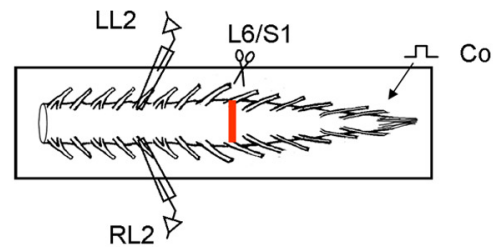

B

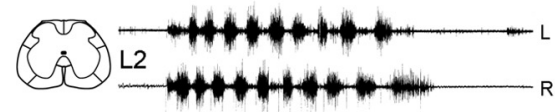

C

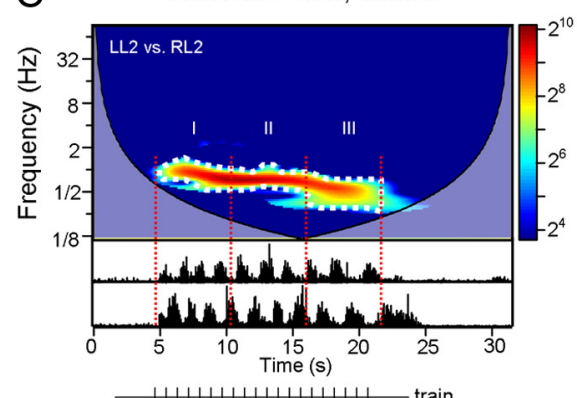

Phase analysis
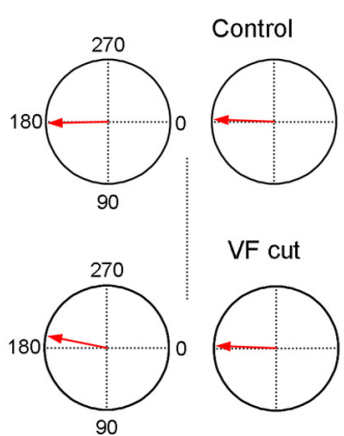

VF cut

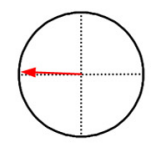

॥

Epoch

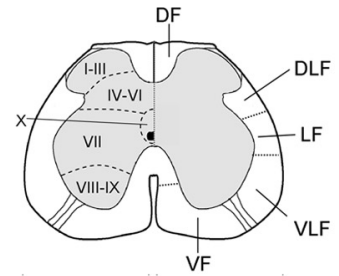

VF cut

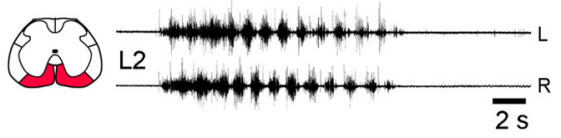

Coherent Power, VF cut

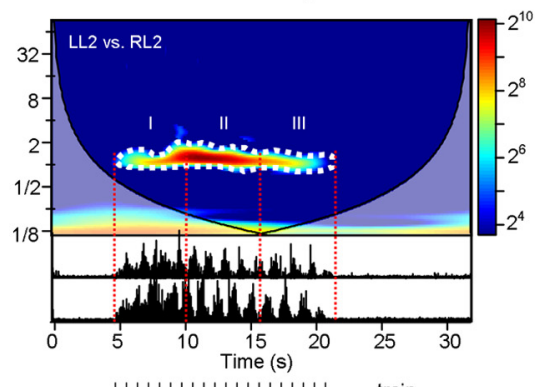

11111111111111111 train

Frequency / Coherence/Power analysis

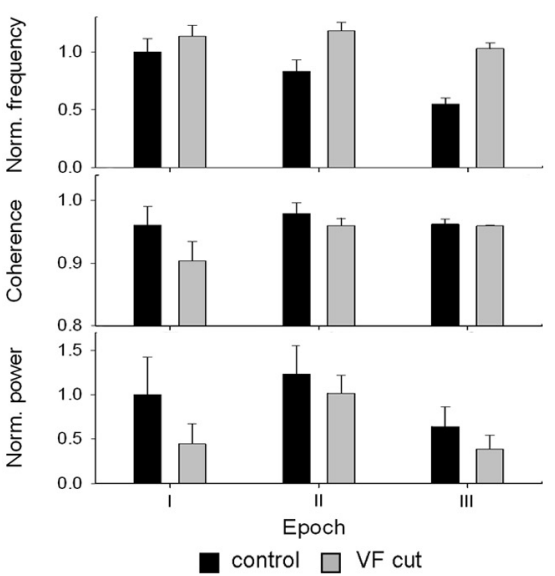

Figure 1. Wavelet analysis of rhythmic bursts produced in the lumbar segments of the spinal cord by stimulation of sacrocaudal afferents. $A$, Schematic illustration of the preparation and the surgical manipulations whose effects on the rhythm are analyzed. The isolated spinal cord preparation of the neonatal rat is shown in the experimental bath (frame). The rhythm is produced by stimulation of the C01 dorsal root (Co1) and recorded from the left and right L2 ventral roots (LL2 and RL2 respectively). The lumbosacral junction at which the ventral funiculi were lesioned (scissors) is denoted by the red bar. The cross section of the spinal cord on the right shows the gray matter laminae $(I-X)$ and the white matter funiculi. DF, DLF, LF, VLF and VF are the dorsal, dorsolateral, lateral, ventrolateral and ventral funiculi, respectively. $\boldsymbol{B}$, Recordings of the rhythm produced by SCA stimulation from the left $(\mathrm{L})$ and right $(\mathrm{R})$ ventral roots of $\mathrm{L} 2$ before (Control), and following a bilateral $\mathrm{VF}$ cut (VF cut) at the lumbosacral junction. The lesioned funiculi are shown in red at the schematic cross section. $C$, The coherent power spectra of the rhythm before and after the bilateral VF lesion (Control and VF cut) are superimposed with the respective rectified data. The high-power regions of interest (ROIs) selected for further analysis are delineated with the white dotted lines, and the 3 consecutive epochs composing each ROI (I, II, and III) are marked by red lines. The stimulus trains are illustrated below each spectrum (trains). Circular plots of the mean left-right phase values and r-vectors (red arrows) at each of the three epochs within each ROI are shown on the lower left (Phase analysis, control and VF cut). The mean normalized frequency, coherence and normalized power during each epoch, before (black bars), and after (gray bars) the bilateral VF cut are superimposed with the respective SD on the lower right (Frequency/Coherence/ Power analysis). Stimulus trains, Control and VF cut: 20 pulse, $1.3 \mathrm{~Hz}$ at 1.1T. Number of trains: 4 Control, 4 VF cut.

\section{Materials and Methods}

Preparations. Spinal cords (T6 to Co3), were isolated from P2-P6 ether anesthetized male or female rats (Lev-Tov and Delvolvé, 2000; Lev-Tov et al., 2000; Delvolvé et al., 2001; Blivis et al., 2007). Preparations were transferred to a recording chamber and superfused continuously with an oxygenated artificial CSF (ACSF) (Kremer and Lev-Tov, 1997; Lev-Tov et al., 2000; Delvolvé et al., 2001; Blivis et al., 2007).

Stimulation and recordings. Suction electrode recordings were obtained from pairs of lumbar and sacral ventral roots using a highgain $\mathrm{DC}$ or $0.1 \mathrm{~Hz}-10 \mathrm{kHz}$ AC amplifier.

Rhythmic activity. Rhythmic activity was induced by electrical stimulation of sacrocaudal afferents (SCAs) mainly in the first and second coccygeal dorsal roots (Co1-Co2). The threshold $(\mathrm{T})$ was measured from the polysynaptic response produced by single pulse stimulation in the ipsilaterally recorded S2 and L2 ventral roots. This threshold was a bit higher comparing to the one required to produce monosynaptic response in Co1-Co2 ventral roots (Blivis et al., 2007). When required, the experimental bath was divided into three compartments by a Vaseline walls to test region-dependent effects of various drugs (see Fig. 5A). The following drugs were used in this work: the non-NMDA receptor blocker CNQX, the NMDA receptor blocker APV and the muscarinic receptor antagonist atropine. White matter lesions: specific lesions of the known divisions of the white matter funiculi were inflicted at the locations specified in the respective parts of the results using ultra fine clipper scissors with $75-\mu \mathrm{m}$ thick blades (Fine Science Tools). Preparations were left for at least $45 \mathrm{~min}$ before attempting to elicit rhythmic activity via SCA stimulation. The microscopic location and extent of the lesions were confirmed by histological examination of $20-\mu \mathrm{m}$-thick cross sections of paraffin embedded preparations after completion of the electrophysiological recordings.

Data acquisition and statistical analysis. Data, were digitized (Digidata 1320A, Molecular Devices), and stored on the computer's hard disk for subsequent analyses (see Gabbay et al., 2002, 2004; Strauss and Lev-Tov, 2003). Population recording data were high-pass filtered at $40-50 \mathrm{~Hz}$, and rectified. All data samples were analyzed using "Spinalcore," a menu driven MATLAB-based program for stationary and nonstationary time series analyses developed by Mor and Lev-Tov (Mor and Lev-Tov, 2007). To speed up the time consuming calculations of the analyses, we exploited graphic processing unit (GPU)-based parallel processing using the NVIDIA-developed Compute Unified Device Architecture (CUDA) (Mor and Lev-Tov, 2008, 2009).

The nonstationary rhythmic patterns produced by activation of the CPGs by SCA stimulation varied with time and their analysis could not be performed by statistical methods that assume data stationarity. Therefore, we used the Wavelet transformation (WT) and WT coherence techniques (Torrence and Compo, 1998) that have been successfully used for automated quantitative analysis of the nonstationary rhythmic patterns produced by activation of the CPGs (Mor and Lev-Tov, 2007). These analyses enabled us to characterize the dynamic portrait of the signals, to assess the linear relation between spectra of any given pair of signals and to uncover hidden components of the rhythm in the time/ frequency domain (Mor and Lev-Tov, 2007). The quantitative parame- 
ters of the rhythm, i.e., the normalized frequency, normalized power, coherence and the phase between pairs of time series data were calculated using density plots of the coherent power spectra, the combined result of the coherence and cross WT spectra, from which noncoherent regions of the cross-wavelet spectrum are omitted (Mor and Lev-Tov, 2007). The analyses are demonstrated in Figure 1 in which we examined the effects of a bilateral lesion of the ventral funiculus (VF) on the capacity of SCA stimulation to produce the thoracolumbar rhythm. The scheme of the experiment and the boundaries of the white matter funiculi are shown in Figure $1 A$ (left and right panels, respectively). The rhythm produced before (control), and after the VF lesion (VF cut) by SCA stimulation and recorded from the left and right ventral roots of L2 is shown in Figure $1 B$. Analyses were performed on the data following the highpass filtering and rectification described above. The coherent power spectra of the data before (control) and after the lesion (VF cut) are shown with the rectified signals in Figure 1C. A main region of interest (ROI) was defined and delineated graphically (dotted white line) within the time/frequency domain of the coherent cross power spectra of the response to each stimulus train. Unless specified differently, this ROI was divided into 12 consecutive bins, for which the means of frequency, power and coherence were calculated. These 12 consecutive means were used to calculate the means of means for 3 equal epochs at the beginning (I), middle (II) and end (III) of the stimulus train (4 means each). The mean left-right phase values and r-vectors were calculated separately for each of the three respective epochs. The statistical significance of the normalized frequency, normalized power and of the coherence was done by multiple comparisons of means using conventional methods of linear statistics (factorial ANOVA and post hoc tests), while the statistical significance of the phase data was obtained using circular statistics procedures for directionality (Rayleigh's test; see Zar, 1999) and multiple comparisons (the Watson-Williams test; see Zar, 1999). The mean left-right phase (phase analysis), frequency, coherence and power values per each epoch (frequency/coherence/power analysis) are shown below the spectra in Figure $1 C$ (for more details see legend).

Fluorescent labeling and confocal microscopy imaging. Fluorescent dextrans (Invitrogen) were used to trace the sacral neurons that are projecting rostrally through the VF, VLF/LF and DLF in neonatal rat spinal cords. Spinal cords were isolated, pinned down in an experimental chamber (vide ante) and superfused with cold oxygenated ACSF $\left(\sim 18^{\circ} \mathrm{C}\right)$. Funicular axons were cut at the lumbosacral junction or caudally to it, placed inside a suction pipette and backfilled with fluorescent dextrans (16.67 mM, molecular weight 10,000) coupled to Fluorescein or Texas Red. After 12-16 h of labeling, the spinal cord was fixed in $4 \%$ paraformaldehyde in 0.01 м PBS, pH 7.4 for $12 \mathrm{~h}$. Consecutive Vibratome sections ( $70 \mu \mathrm{m}$ thick) were cut and the labeling was viewed using confocal microscopy (Fluoview 1000 Olympus). Confocal imaging of the labeled pathways in whole mount preparations (see Figs. 6, 7) was performed following dehydration of the fixed spinal cord in an ascending series of alcohols and overnight immersion of the labeled

B
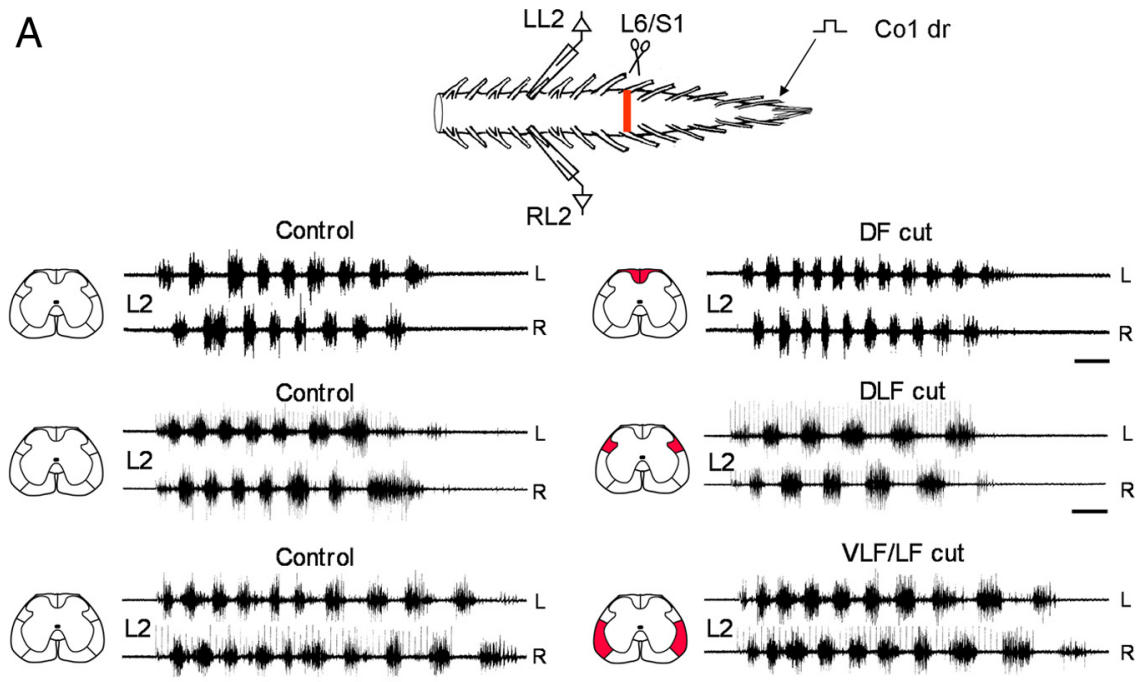

Control
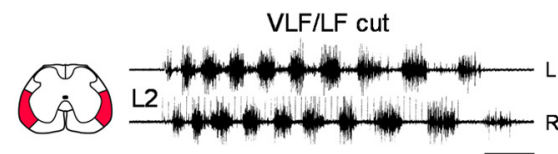

Control

VF cut
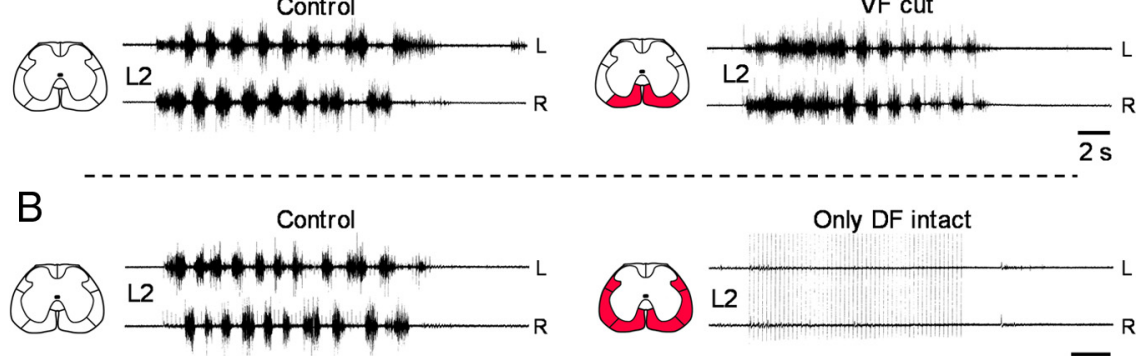

Control
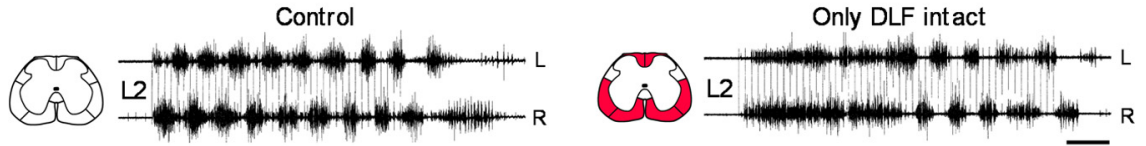

Control
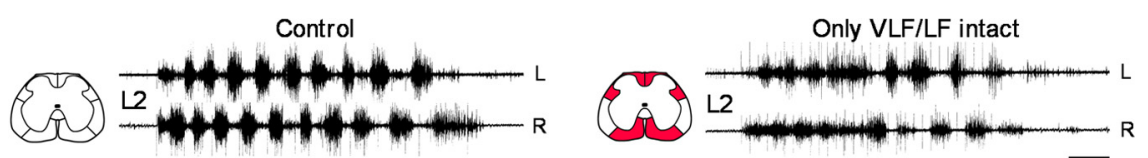

Control

Only VF intact
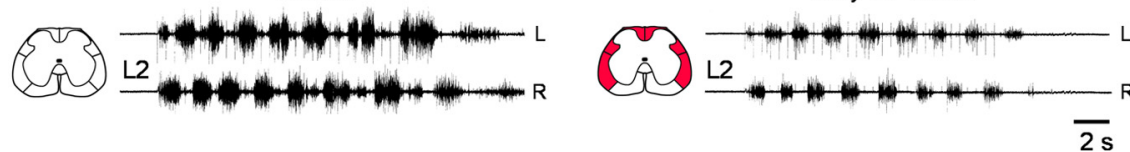

Only DF intact
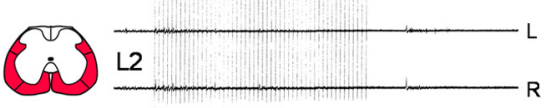

Figure 2. Effects of funicular lesions on the lumbar rhythm produced by SCA stimulation. $A$, Recordings from the left and right $L 2$ ventral root in 4 different experiments during stimulation of the $C 01$ dorsal root before (Control), and after bilateral interruption of the DF (DF cut), DLF (DLF cut), VLF/LF(VLF/LF cut) and VF(VF cut). The lesioned funiculiare shown in red in the schematic cross sections (left to each set of traces). Stimulus trains (control and the respective postlesion recordings), DF cut: 60 pulse, $4 \mathrm{~Hz}, 1.7 \mathrm{~T}$; DLF cut: 50 pulse, 3.3 Hz, 1.2T; VLF/LF cut: 50 pulse, 4Hz, 1.25T; VF cut:20 pulse, 1.3 Hzat 1.1T Note that the VLFlesionsincluded the LF. Thereforethese lesions are referred to as VLF/LF lesions throughout the present study. $B$, Recordings from the left and right $L 2$ ventral root in 4 different experiments during stimulation of the C 1 dorsal root before (Control), and after bilateral interruption of the VF, VLF/LF and DLF (only DF intact), the VF, VLF/LF and DF (only DLF intact), the VF, DLFand DF (only VLF/LFintact) and the VLF/LF, DLF and DF (only VFintact). The lesioned funiculiare shown in red in the schematic cross sections (left to each set of traces). Stimulus trains: only DF intact: 50 pulse, $4 \mathrm{~Hz}, 1.7 \mathrm{~T}$ (control) and 8.3T (postlesion); only DLF intact 40 and 50 pulse (control and postlesions), $3.3 \mathrm{~Hz}, 1.9 \mathrm{~T}$; only VLF/LF intact: 20 pulse, $1.3 \mathrm{~Hz}, 1.1 \mathrm{~T}$ (control), 30 pulse $2 \mathrm{~Hz}$, 1.9T (postlesions); only VF intact: 30 pulse, $2 \mathrm{~Hz}, 1.2 \mathrm{~T}$. Calibration bars $(\boldsymbol{A}, \boldsymbol{B}), 2 \mathrm{~s}$.

preparations in a mixture of benzyl alcohol and benzylbenzoate (Dodt et al., 2007). Labeled neurons could usually be detected in these transparent preparations throughout the depth of the spinal cord (up to $1000 \mu \mathrm{m}$ ).

\section{Results}

The funicular pathways involved in activation of the CPGs by sacrocaudal input

Our previous studies revealed that there are no direct synaptic contacts between SCAs and the hindlimb CPGs, and that the sacral neurons activated by the afferents to produce the rhythm, 


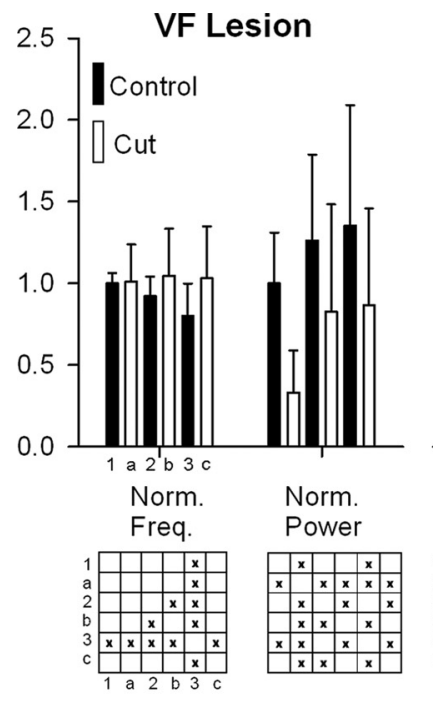

VLF/LF Lesion

DLF Lesion

DF Lesion

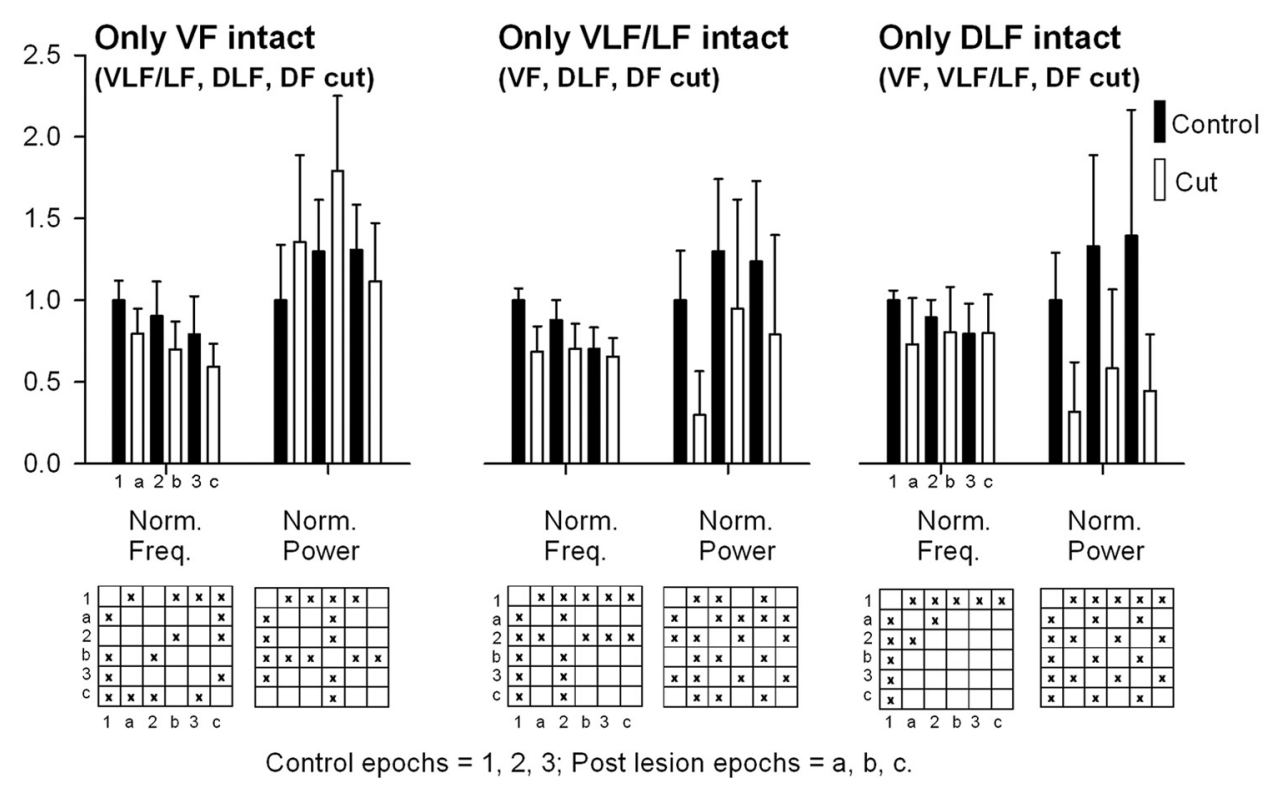

Figure 3. Effects of funicular lesions on the frequency and power of the lumbar rhythm produced by SCA stimulation. The means \pm SDs of the normalized frequency and power (norm. freq., norm. power) of the rhythm produced by SCA stimulation and recorded from the left and right ventral roots of $\mathrm{L} 2$ before (Control, black histograms) and after surgical manipulations of the white matter funiculi (Cut, white histograms) are shown for the three epochs sampled during the stimulus trains (epochs I, II, and III are numbered 1, 2, 3 for the Control and a-c for the postlesion period, respectively). The matrices below each set of histograms show the results of the multiple-comparison tests performed using the modified Tukey's method. Significant differences (starting from $p<$ 0.05 ) are denoted by $X$. The number of experiments was as follows: VF lesion $=9$, VLF/LF lesion $=4$, DLF lesion $=4$, DF lesion $=4$, Only VF intact $=3$, Only VLF/LF intact $=6$, only DLF intact $=$ 4 , only DF intact (data not shown) $=5$. The number of trains in each experiment was 8 ( 4 control, and 4 postlesion trains).

project rostrally through the white matter funiculi (Strauss and Lev-Tov, 2003). In the first part of this study, we examined the effects of various funicular lesions on the ability of SCA stimulation to produce the rhythm. First, we studied the effects of interruption of specific white matter funiculi on the rhythm, then the effects of multifunicular lesions that spared only one of the funiculi and finally the effects of funicular lesions at multiple levels of the sacral cord.

The effects of interruption of specific white matter funiculi on the rhythm are demonstrated in Figure $2 A$. The control rhythm (Fig. $2 \mathrm{~A}$, Control, left column) in all the experiments performed in this series, persisted after a bilateral lesion of any of the white matter funiculi (DF, DLF, VLF/LF and VF, respectively; Fig. $2 \mathrm{~A}$, right column). The rhythm slowed following a bilateral DLF lesion and it was mixed with tonic firing at the beginning of the stimulus trains after a bilateral lesion of the VF.
The effects of multifunicular lesions that spared only one of the funiculi on the rhythm are shown in Figure $2 B$. The rhythm was totally blocked following a bilateral interruption of the VF, VLF/LF and DLF (only DF intact) at the lumbosacral junction, but it persisted following a combined lesion of the VF, VLF/LF and DF (only DLF intact), following a bilateral interruption of the VF, DLF and DF (only VLF/LF intact), and also after a bilateral interruption of the VLF/LF, DLF and DF (only VF intact). It should be noted that the rhythm produced by SCA stimulation after a specific lesion of the VF or after combined lesions that included the VF (only DLF and only VLF/LF intact), exhibited a similar pattern. This pattern was characterized by a period of bilateral tonic activity mixed with rhythmic bursting at the beginning of the stimulus trains. Then, the tonic activity changed to a regular alternating left-right pattern that persisted till the end of the stimulation. 


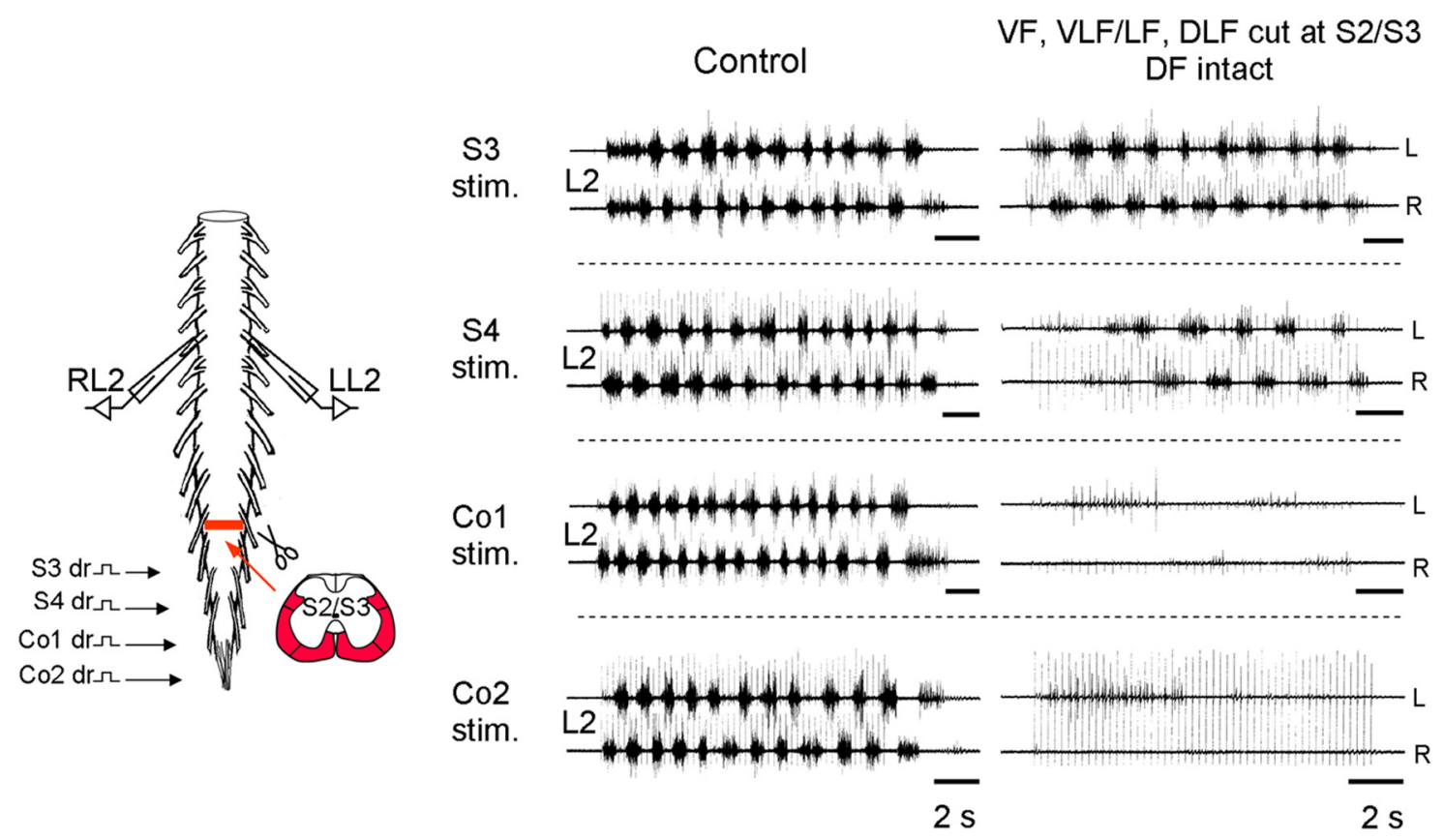

Figure 4. Activation of nonsegmental sacral relay neurons by SCA stimulation through the sacral dorsal columns. Recordings from the left and right L2 ventral roots in one of the experiments during stimulation of the $\mathrm{C} 02, \mathrm{C} 01, \mathrm{~S} 4$ and $\mathrm{S} 3$ dorsal roots respectively, before (Control), and after a bilateral lesion that interrupted the VF, VLF/LF and DLF at $S 2 / S 3$ border and left the DF as the only bilaterally intact funiculus. Stimulus trains, $S 3: 40$ pulse $3 \mathrm{~Hz}, 1.9 \mathrm{~T}$ (control), 60 pulse $4 \mathrm{~Hz}, 1.25 \mathrm{~T}$ (postlesions); $54: 50$ pulse $3 \mathrm{~Hz}, 2 \mathrm{~T}$ (control), 40 pulse $3 \mathrm{~Hz}, 1.3 \mathrm{~T}$ (postlesions); Co1: 40 and 50 pulse (control and postlesions), $3 \mathrm{~Hz}, 1.25 \mathrm{~T}$; C02: 50 pulse, $4 \mathrm{~Hz}$, 2.5T (control and postlesions).

The data obtained in all the lesion experiments were analyzed using the WT and WT coherence techniques as described in Materials and Methods (Fig. 1). The parameters of the rhythm (frequency, coherence and power) before, and after the lesions, were extracted from the coherent power spectra and analyzed using factorial ANOVA followed by post hoc multiple comparisons. The left-right phase values were calculated from the complex numbers of the coherent power matrices, analyzed using circular statistics, and compared using the Watson and Williams method for multiple comparisons (see Materials and Methods). These analyses revealed that the lesions performed in this series affected most significantly the frequency and the power of the time series while the left-right phase values remained virtually unaltered. There were some effects of the lesions on the cross coherence, however these were rather small. Summarizing plots of the mean normalized frequency and the mean normalized power of the rhythm before and after the surgical manipulations are shown in Figure 3.

These analyses revealed that the rhythm in all the control experiments (black histograms in each set) was characterized by a significant decrease in the frequency during the stimulus trains (the mean frequency in epoch I was always significantly higher than in epoch III, factorial ANOVA, $p \ll 0.01$, followed by the modified Tukey method, $p \ll 0.05)$ and by a significant increase in normalized power (the mean normalized power in the middle of the train (epoch II) was higher than the mean at the beginning of the train (epoch I)). This difference was statistically significant (factorial ANOVA, $p \ll 0.01$, followed by the modified Tukey method, $p \ll 0.01$ ) in 5 of the 7 series of experiments performed in this part. The mean power in epoch II was either higher than the mean of the normalized power at end of the train (epoch III), or similar to it in $2 / 7$ and $5 / 7$ series of experiments, respectively. As mentioned above, the mean coherence and the mean left-right phase shift remained unaltered throughout the duration of the stimulus trains in all the control experiments.
The white histograms in each dataset in Figure 3 show the effects of lesions of the white matter funiculi on the SCA-induced rhythm. The effects of lesions that included the VF (VF cut, only VLF/LF intact, only DLF intact) were different from those that spared the VF (only VF intact, VLF/LF cut, DLF cut, DF cut). Following VF lesions the rhythm was characterized by lack of changes in the mean normalized frequency during the 3 epochs. The kinetics of changes in power during the trains was not altered compared with control. However, there were significant changes in the mean normalized power: the mean normalized power in the 3 examined epochs following VF lesion, VF/ DLF/DF lesion (only VLF/LF intact) and following VF/(VLF/LF)/ DF lesion (only DLF intact) was significantly lower compared with the mean power during the respective epochs in the control series (ANOVA, followed by Tukey method, $p \ll 0.02$ ).

The rhythm following lesions that spared the VF was characterized by decay in frequency during the stimulus trains that was similar to that of the control. However, while lesions of the VLF/LF and DF did not affect the mean normalized frequency in the 3 epochs, lesions of the DLF and the DLF together with the VLF/LF and the DF (only VF intact) decreased the mean normalized frequency in epoch I, II and III compared with the respective means of the control series in these epochs, factorial ANOVA $(p \ll 0.001)$ followed by the modified Tukey method ( $p<0.03$, for epoch I, DLF lesion, and $p \ll 0.001$ for epoch II and III DLF lesion, and for epoch I, II and III after (VLF/LF)/DLF/DF lesion (only VF intact)). The kinetics of changes in power during the train was not altered. Lesions of the VLF/LF, DLF, or DF did not affect the mean normalized power in the 3 epochs compared with the respective means of the control in these epochs. However, the mean normalized power in the 3 epochs after (VLF/LF)/DLF/DF lesion (only VF intact) was significantly higher than the respective means of the control in these epochs; factorial ANOVA ( $p$ $\ll 0.001)$ followed by the modified Tukey method $(p<0.001)$. 
A
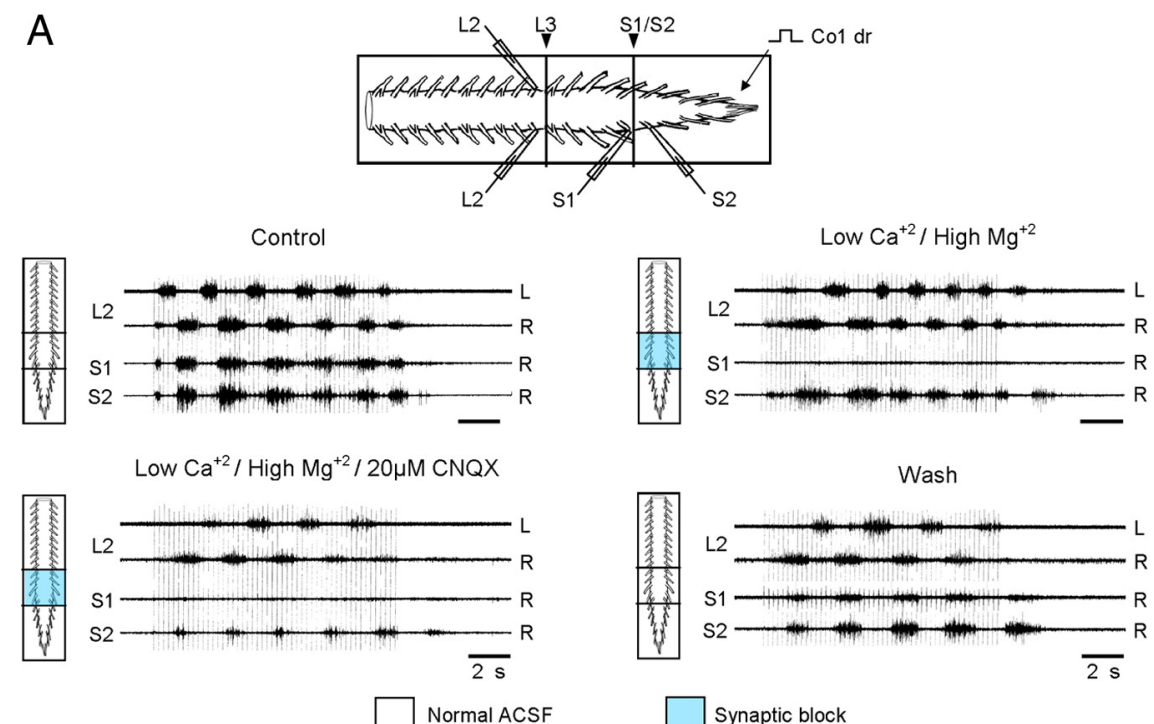

B
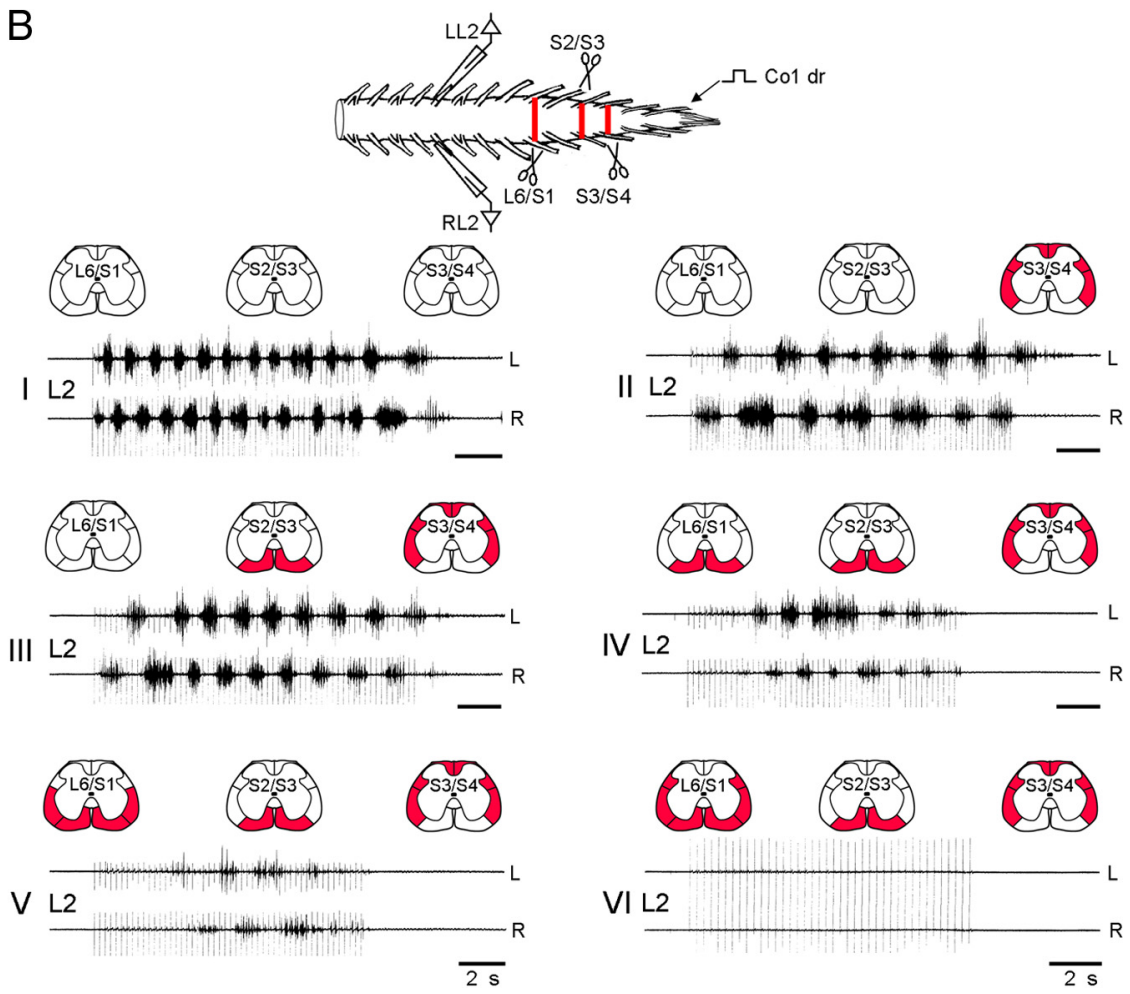

Figure 5. The involvement of sacral neurons with long and short ascending projections in the generation of the lumbar rhythm by SCA stimulation. $A$, The SCA-induced rhythm can be produced by activation of sacral neurons with long ascending projections. Schematic illustration of the experimental setting is shown on top. The preparation is mounted with ventral side up in an experimental bath that was divided into a rostral ( $T 6$ to caudal L2), middle (caudal L2 to rostral S2), and a caudal (rostral S2 to C03) compartments, by Vaseline wall. The rhythm was produced by stimulation of the C 01 dorsal root and recordings were obtained from the left and right $L 2$ ventral roots, and from the right $S 1$ and $S 2$ ventral roots. The rhythm was produced by stimulation of the Co1 dorsal root before (Control), after blocking the synaptic transmission from caudal $\mathrm{L} 2$ to rostral $\mathrm{S} 2$ by changing the bathing medium in the middle chamber from ACSF to low $\mathrm{Ca}^{+2} / \mathrm{high} \mathrm{Mg}^{+2} \mathrm{ACSF}\left(\mathrm{Low} \mathrm{Ca}^{+2} / \mathrm{high} \mathrm{Mg}^{+2}\right)$ and then adding $20 \mu \mathrm{m} \mathrm{CNQX}$ ( Low Ca ${ }^{+2} / \mathrm{High} \mathrm{Mg}^{+2} / 20 \mu \mathrm{M}$ CNQX). Recordings were also obtained after alleviation of the block following 30 min wash (Wash). Stimulus trains: 50 pulse, $4 \mathrm{~Hz}, 2.4 \mathrm{~T}$. $\boldsymbol{B}$, The lumbar CPGs can be activated by SCA stimulation when the direct contacts made by long-ascending axons from the sacral neurons are interrupted. The scheme on top shows the preparation and the experimental paradigm that was used in this series. The rhythm was produced by stimulation of the $\mathrm{C} 01$ dorsal root and recorded from the left and right $\mathrm{L} 2$ ventral root. The preparation was surgically manipulated at three segmental levels $\mathrm{S} 3 / \mathrm{S} 4, \mathrm{~S} 2 / \mathrm{S} 3$ and $\mathrm{L} 6 / \mathrm{S} 1$ (red bars in the top, and red fills in the schematic cross sections above each set of traces). The rhythm is shown before (I), after cutting the $\mathrm{VLF} / \mathrm{LF}$, DLF and DF at the $\mathrm{S} 3 / \mathrm{S} 4$ border and leaving the VF as the only intact funiculi (II), after bilateral interruption of the VF at the S2/S3 (III) and L6/S1 level (IV), extension of this latter lesion to the VLF/LF (V) and DLF (VI). Stimulus trains: 50 (I, III, V) and 60 (II, II) pulse at $4 \mathrm{~Hz}, 1.75 \mathrm{~T} ; 40$ pulse, $3 \mathrm{~Hz}$ at $2.5 \mathrm{~T}$ (VI).

\section{Activation of nonsegmental relay neurons through the sacral dorsal columns.}

The experiments described above revealed that the ability of SCA stimulation to activate the hindlimb CPGs is totally blocked following funicular lesions at the lumbosacral junction that spared the DF as the only bilaterally intact funiculi (Fig. $2 B)$. This finding is consistent with our previous reports that there is no direct connectivity between the afferents and the hindlimb CPGs (Strauss and Lev-Tov, 2003). However, it is possible that dorsal columns afferents can activate sacral relay neurons that are not located in the sacral segment onto which the stimulated dorsal roots are attached (nonsegmental relay neurons) whose axons project rostrally through other white matter funiculi to produce the rhythm. To examine this possibility, we interrupted the VF, VLF/LF and DLF at the S2/S3 border, left the DF intact and tested whether stimulation of dorsal roots that enter the cord caudally to the multifunicular lesion can bypass the lesion through the intact dorsal columns and activate nonsegmental relay neurons rostral to the lesion to produce the rhythm. Figure 4 shows that the rhythm could be produced reliably only by stimulation of the adjacent S3 and S4 dorsal roots. Stimulation of the Col dorsal root produced few weak bursts of very few motoneurons and stimulation of the $\mathrm{Co} 2$ dorsal root failed to produce the rhythm. These findings were repeated in 5 experiments. In summary, a robust rhythm could be produced by stimulating dorsal roots that were no further than 2 segments from the multifunicular lesion that spared the DF. Thus, despite the fact that there are no direct connections between SCA and the hindlimb CPG, dorsal columns afferents can activate nearby nonsegmental sacral relay neurons that project rostrally through other white matter funiculi to produce the rhythm.

\section{Are the hindlimb CPGs activated by} direct projections from the sacral neurons during SCA stimulation?

The sacral neurons activated by the SCA stimulation that produce the rhythm may include propriospinal neurons and/or tract neurons with spinal collaterals. Theoretically, these sacral neurons can activate the CPGs either directly or indirectly, by recruiting additional groups of propriospinal neurons that are interposed between the second-order relay neurons and the CPGs. To examine these possibilities, we performed two series of experiments. 
Table 1. The mean parameters of the rhythm produced in the control series, after cutting the white matter funiculi at $\mathrm{S} / \mathrm{S} 4$ and sparing only the $\mathrm{VF}$, and after the bilateral interruption of the intact VF at $\mathbf{S 2} / \mathbf{S 3}$

\begin{tabular}{|c|c|c|c|c|}
\hline Parameter & Epoch & Control & Only VF intact at S3/S4 & VF cut at $S 2 / S 3$ \\
\hline \multirow[t]{3}{*}{ Normalized frequency } & I & $1.0 \pm 0.11$ & $0.49 \pm 0.17$ & $0.54 \pm 0.24$ \\
\hline & $\|$ & $0.94 \pm 0.15$ & $0.47 \pm 0.13$ & $0.58 \pm 0.24$ \\
\hline & III & $0.83 \pm 0.18$ & $0.43 \pm 0.12$ & $0.54 \pm 0.23$ \\
\hline \multirow[t]{3}{*}{ Coherence } & I & $0.88 \pm 0.05$ & $0.85 \pm 0.04$ & $0.85 \pm 0.05$ \\
\hline & $\|$ & $0.9 \pm 0.03$ & $0.88 \pm 0.04$ & $0.87 \pm 0.06$ \\
\hline & III & $0.9 \pm 0.03$ & $0.89 \pm 0.05$ & $0.86 \pm 0.06$ \\
\hline \multirow[t]{3}{*}{ Normalized power } & I & $1.0 \pm 0.33$ & $1.59 \pm 1.05$ & $1.06 \pm 0.9$ \\
\hline & $\|$ & $1.19 \pm 0.49$ & $2.3 \pm 1.54$ & $1.58 \pm 1.61$ \\
\hline & III & $1.13 \pm 0.77$ & $1.8 \pm 1.56$ & $0.96 \pm 1.23$ \\
\hline \multirow[t]{6}{*}{ Phase (r vector) } & I & $181.8 \pm 12.7^{\circ}$ & $182.2 \pm 13^{\circ}$ & $178.4 \pm 23.1^{\circ}$ \\
\hline & & $(0.98)$ & $(0.98)$ & $(0.92)$ \\
\hline & $\|$ & $180.5 \pm 12.0^{\circ}$ & $181.2 \pm 11.1^{\circ}$ & $178 \pm 14.7^{\circ}$ \\
\hline & & $(0.98)$ & $(0.98)$ & $(0.97)$ \\
\hline & III & $181.9 \pm 9.98^{\circ}$ & $183.6 \pm 12.94^{\circ}$ & $176.5 \pm 19^{\circ}$ \\
\hline & & $(0.99)$ & $(0.98)$ & $(0.95)$ \\
\hline
\end{tabular}

For further details, see bottom of this page.

In the first series we blocked synaptic transmission in the 5 spinal segments between S2 and L2 and tried to generate the rhythm in L2 by stimulation of sacrocaudal afferents. In the second series, we interrupted the VLF/LF, DLF and DF bilaterally at the S3/S4 junction, elicited the rhythm by activation of sacral neurons whose axons project rostrally only through the VF, and then examined the effects of bilateral interruptions of the intact $\mathrm{VF}$ at the S2/S3 and L6/S1 junctions.

Figure $5 A$ shows the scheme of the first series of experiments described above. The experimental bath was divided into a rostral (T6 to caudal L2), middle (caudal L2 to rostral S2), and a caudal (rostral S2 to Co3) compartments and we tested whether stimulation of the Col dorsal root produces rhythmic activity in the rostral lumbar segments before, and after blocking the synaptic transmission in the middle compartment. The rhythm recorded from the left and right L2 ventral root persisted following 45-60 min exposure of the L3-S1 segments in the middle compartment to low-calcium (0.1 mM), high magnesium (5-15 mM) ACSF. The rhythm persisted also after further addition of $20 \mu \mathrm{M}$ nonNMDA receptor blocker CNQX to this compartment. Seven experiments were performed in this series. The L 2 rhythm could be produced in each of these experiments (7/7) in the presence of low $\mathrm{Ca}^{2+} /$ high $\mathrm{Mg}^{2+}$ ACSF in the middle compartment. Addition of $20 \mu \mathrm{M}$ CNQX to the low $\mathrm{Ca}^{2+} /$ high $\mathrm{Mg}^{2+}$ ACSF (2 experiments) or $20 \mu \mathrm{M}$ CNQX, $100 \mu \mathrm{M}$ AP5 and $100 \mu \mathrm{M}$ Atropine (5 experiments), blocked the L2 rhythm in one experiment, but not in 6 of the remaining experiments. However, in 2/6 of the experiments the L 2 rhythm could not be elicited $30 \mathrm{~min}$ after the addition of CNQX/AP5/atropine to the low $\mathrm{Ca}^{2+} /$ high $\mathrm{Mg}^{2+}$ ACSF. Statistical analyses of the rhythm recorded from L2 (see Materials and Methods) revealed that the mean normalized frequency in epoch II of the control series $(1 \pm 0.14)$ was not altered $(1.12 \pm 0.33)$ as the L3-S1 segments were exposed to low $\mathrm{Ca}^{2+}$ / high $\mathrm{Mg}^{2+}$ ACSF or to low $\mathrm{Ca}^{2+} /$ high $\mathrm{Mg}^{2+}$ ACSF containing either CNQX or CNQX/ AP5/atropine $(0.9 \pm 0.3)$. The mean coherence under these conditions was $0.92 \pm 0.03,0.89 \pm 0.06$, and $0.92 \pm 0.03$, respectively. The mean normalized power in epoch II of the control series $(1.13 \pm 0.4)$, decreased significantly to $0.65 \pm 0.3\left(\right.$ low $\mathrm{Ca}^{2+} /$ high $\left.\mathrm{Mg}^{2+}\right)$ and $0.77 \pm 0.37\left(\right.$ low $\mathrm{Ca}^{2+}$ / high $\mathrm{Mg}^{2+}$ with CNQX or CNQX/AP5/atropine). The mean phase values remained unaltered $179 \pm 11,182 \pm 25$ and $176 \pm$ $9^{\circ}$ under these conditions and the r-vector values were $0.98,0.91$ and 0.988 , respectively.
These results indicate that activation of propriospinal neurons with long axons that originate in S2 or below can activate the lumbar CPG in the absence of short range propriospinal projections.

The second possibility to produce the lumbar rhythm is by consecutive recruitment of groups of propriospinal neurons that are interposed between the second-order relay neurons and the CPGs. In an additional series of experiments demonstrated in Figure $5 B$, the preparations were surgically manipulated at three segmental levels S3/S4, S2/S3 and L6/S1 (red bars, top, and red fills in the schematic cross sections above each set of traces). The rhythm was generated by stimulation of the Col dorsal root and recorded from the left and right L2 ventral roots. The control rhythm (I) persisted following a bilateral transection of (VLF/ LF)/DLF/DF at the S3/S4 junction (II). This rhythm was elicited only by the sacral neurons whose axons project rostrally through the spared VF. Under these conditions, bilateral interruption of the sacral VF first at the S2/S3 junction (III) and then at the L6/S1 junction (IV) did not block the rhythm produced by SCA stimulation. Moreover, the rhythm persisted even after extension of the VF lesion to the VLF/LF at the L6/S1 junction (V), and was blocked only after further extension of the L6/S1 lesion to the DLF (VI). It should be noted however, that after the second VF lesion (IV) and after its extension to the VLF/LF, the appearance of the rhythm was delayed; the firing intensity initially increased and then declined toward the end of the stimulus train. Twelve experiments were performed in this series. The rhythm produced by activation of sacral neurons whose axons projected rostrally through the VF, persisted following the bilateral interruption of the VF at S2/S3 in each of these experiments (12/12).

Analysis of the rhythm produced by activation of the sacral neurons whose axons project through the VF before (only VF intact) and after the bilateral interruption of the VF at S2/S3, revealed that the main changes occurred in normalized frequency and normalized power of the rhythm (Table 1). The decrease in frequency during the stimulus trains that was typical to the control series, was also found for the rhythm mediated by the intact VF at S3/S4 (ANOVA for the epoch means, $p \ll 0.0001$ ), but not the rhythm produced following VF cut at S2/S3. A small increase in the mean normalized frequency was found in epoch II and III following the VF cut at S2/S3 compared with the means observed for the intact VF at S2/S3 [factorial ANOVA $(p<0.001)$ followed by the modified Tukey method, $p<0.01]$. The mean normalized 


\section{A VF fill at L6/S1, ventral view}
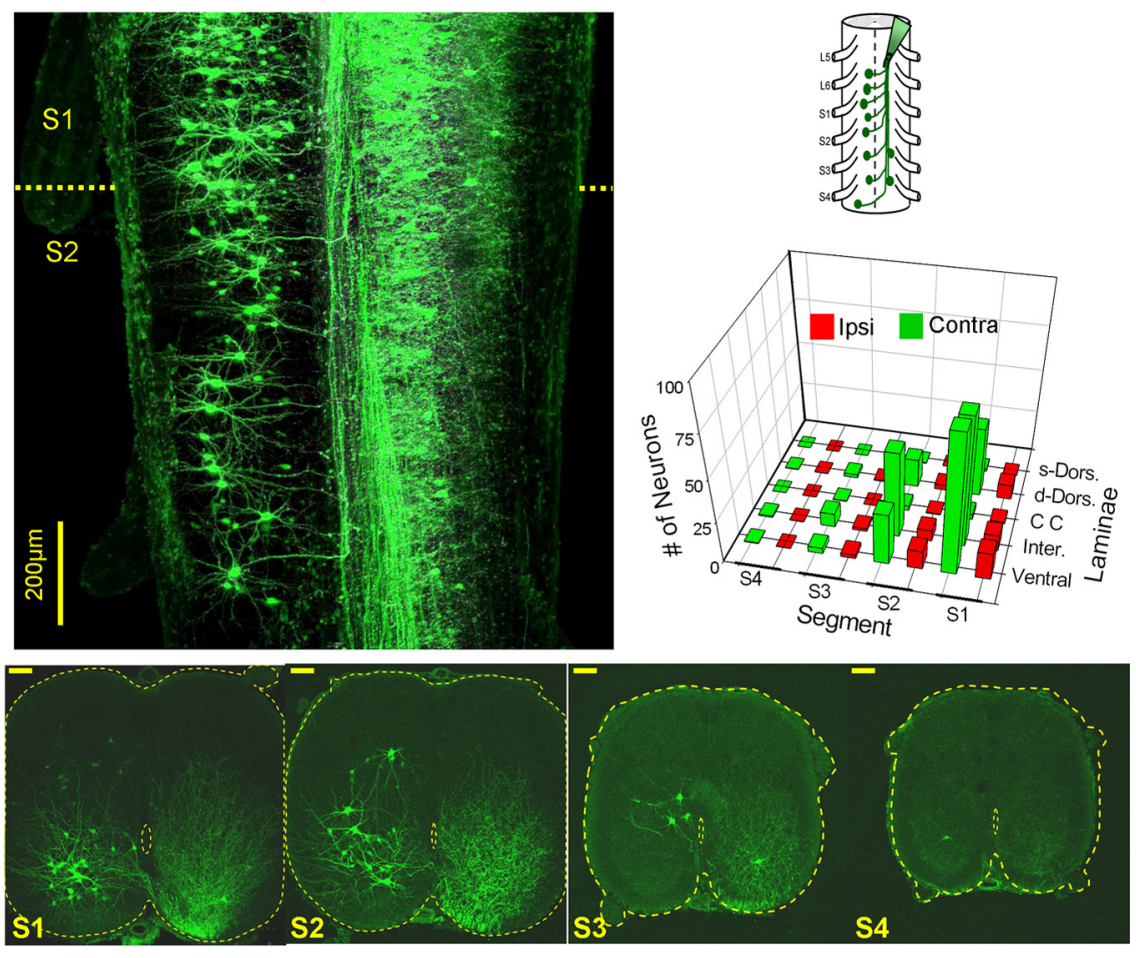

B VF fill at the left S2/S3
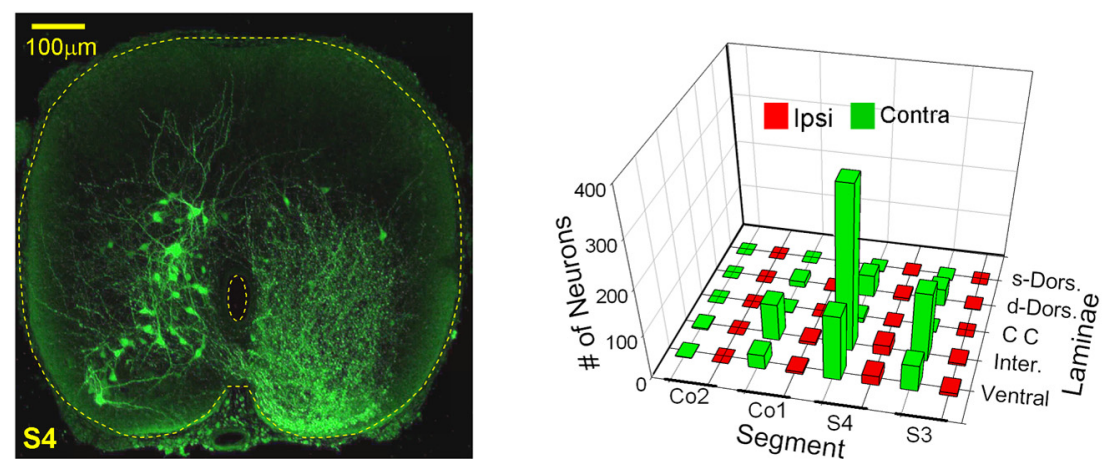

Figure 6. Rostrally projecting VF neurons. A, Schematic ventral view of backfilling of cut VF axon bundles with fluorescein dextran at the left lumbosacral junction is shown on the right. A projected confocal image of sacral neurons labeled through the cut VF axons at the left lumbosacral junction in a whole mount transparent preparation of the spinal cord. This image is composed of a sample of 20 consecutive optical slices, $8 \mu \mathrm{m}$ each, scanned from the ventral aspect of the whole mount preparation. Projected confocal images of $70-\mu \mathrm{m}$-thick cross sections through the $\mathrm{S1}, \mathrm{S} 2, \mathrm{~S} 3$ and $\mathrm{S} 4$ of a different preparation are superimposed below. Calibration bars: $100 \mu \mathrm{m}$; the perimeter of the cross sections and the central canal are delineated by dashed lines. Note the predominance of contralaterally filled neurons, the decrease in the number of cells in the caudal direction and, the course of the crossing axons onto the ascending VF. The three dimensional histogram on the right shows the mean segmental and laminar distribution of contra (green) and ipsilaterally (red) labeled neurons in the 12 labeling experiments performed in this series. $s$ - and d-Dorsal, Superficial (laminae I-IV) and deep (laminae V and VI) dorsal laminae; respectively; $C$, laminae X neurons around the central canal; Inter., lamina VII; Ventral, laminae VIII and IX. $B$, Confocal projected image of cross section through the $S 4$ segment following retrograde VF labeling with fluorescein dextran loaded via the cut VF at the S2/S3 junction. The segmental and laminar distribution of the labeled neurons in 3 experiments is shown in a $3 \mathrm{D}$ histogram on the left. Note that neurons were labeled in S3-C02 mainly contralateral to the fill. The projected image is composed of 10 optical slices, $8 \mu \mathrm{m}$ each. For abbreviations, see Fig. $6 \mathrm{~A}$.

power that was increased significantly compared with control when the VF was left as the only intact funiculi at S3/S4, decreased significantly for each of the three respective epochs following the bilateral interruption of the VF at the S2/S3 [factorial ANOVA $(p<0.001)$ followed by the modified Tukey method, $p<0.01]$. There was a significant drop in power toward the end of the rhythm (the mean in epoch III < epoch II, but was not different from the mean power in epoch I) after the interruption of the VLF/LF, DLF and LF at S3/4, and after cutting the $\mathrm{VF}$ at S2/S3 [factorial ANOVA $(p<0.001)$ followed by the modified Tukey method, $p<0.01]$. The left-right phase shift was not altered by the lesions.

In 11 of the experiments we interrupted the VF not only at S2/S3 but also at the L6/S1 level. The rhythm persisted under these conditions in $8 / 11$ experiments. However, in $44 \%$ of the stimulus trains, it started after an initial delay and/or decayed before the end of the stimulus trains. In these cases the duration of the rhythm during the stimulus trains was shortened by $26.5 \pm 11.7 \%$. Analysis of the rhythm at the middle of the stimulus trains (epoch II) under these conditions revealed that the mean normalized frequency was $0.68 \pm 0.32$ (significant increase compared with the respective mean of the normalized frequency after the S2/S3 VF cut; see Table 1), the mean coherence was $0.85 \pm 0.06$, the mean normalized power was $1.29 \pm 1.2$, and the mean left-right phase shift was $178.7 \pm$ $35.3^{\circ}, \mathrm{r}$-vector $=0.83$. These values were similar to those observed following the S2/S3 cuts.

In summary, the results of this series of experiments suggested that activation of propriospinal neurons with short range multifunicular projections is sufficient to produce the rhythm by SCA stimulation despite the disruption of the long axonal projections of the sacral neurons to the lumbar cord.

The crossed and uncrossed pathways projecting via the sacral VF, VLF/LF, and DLF

The surgical manipulation experiments described above suggested that pathways projecting rostrally through the VF, VLF/LF and DLF are activated by SCA stimulation to produce the rhythm. In the series of experiments described below, we backfilled sacral neurons with fluorescent dextrans through bundles of cut funicular axons at the lumbosacral junction and studied the spatial distribution of these neurons and the anatomical organization of their rostral projections using confocal microscopy.

\section{VF projections}

Figure $6 \mathrm{~A}$ shows a projected confocal image of a transparent whole mount spinal cord preparation (see Materials and Methods) following a retrograde labeling of cut VF axons at the L6/S1 junction (upper left panel). Most of the neurons were contralat- 
eral to the fill. The number of the labeled neurons decreased caudal to the fill site, and the axons of the contralateral neurons crossed the cord through the ventral commissure and ascended rostrally. Thin serial sections of the labeled preparations were used to study the laminar and segmental distribution of the sacral relay neurons (Methods). Confocal micrographs of cross sections through S1, S2, S3 and S4 following L6/S1 VF fill in one of the preparations, are shown on the bottom of Figure $6 \mathrm{~A}$. These micrographs show a dense ipsilateral neuropil of labeled VF fibers with retrogradely labeled interneurons and tract neurons located mainly contralateral to the fill. These neurons were distributed in the dorsal laminae (IV,V,VI in S1; IV,V in S2-Co1), intermediate lamina (VII), lamina $\mathrm{X}$ and ventral laminae (VIII, IX) of the gray matter. Three dimensional histograms describing the laminar and segmental locations of the VF neurons in 12 different L6/S1 VF fills are shown at the lower right panel of Figure $6 \mathrm{~A}$. Most of the neurons were found within the contralateral laminae VII, VIII and IX. Interestingly, rather few neurons were labeled in the caudal sacral segments and the majority of the labeled neurons had short rostral projections (see also the cross sections in Fig. 6A). Because our studies revealed that the sacral relay neurons that are close to the stimulated dorsal root (Co1 or S4) are also likely to play a major role in the generation of the lumbar rhythm by SCA stimulation (Fig. 5B), we back filled the cut VF at the S3 level, and studied the spatial distribution of the labeled neurons in S4, Co1 and Co2 using confocal microscopy. Figure $6 B$, shows a confocal projected image of neurons labeled in a cross section through the $\mathrm{S} 4 \mathrm{seg}$ ment following an S2/S3 VF fill, and the segmental and laminar distribution of the neurons labeled through the cut S2/S3 VF in 3 experiments [three-dimensional (3D) histogram]. The predominant contralateral labeling ( $92 \%$ of the neurons) and the laminar distribution of the labeled neurons were generally similar to those observed following L6/S1 labeling in the more rostral sacral segments.

\section{VLF/LF projections}

Back labeling studies of cut VLF/LF axons were performed in 10 experiments ( 5 whole mount preparations and 5 that were cut in $70-\mu \mathrm{m}$-thick cross sections). Confocal micrographs of a labeled whole mount preparation and examples of labeled neurons in thin cross sections through each of the sacral segments and the first coccygeal segment in a different preparation are shown in Figure 7. These micrographs show that numerous VLF/LF neurons were labeled ipsilaterally to the fill in the first and second sacral segments (Fig. 7, S1). The number of the labeled neurons
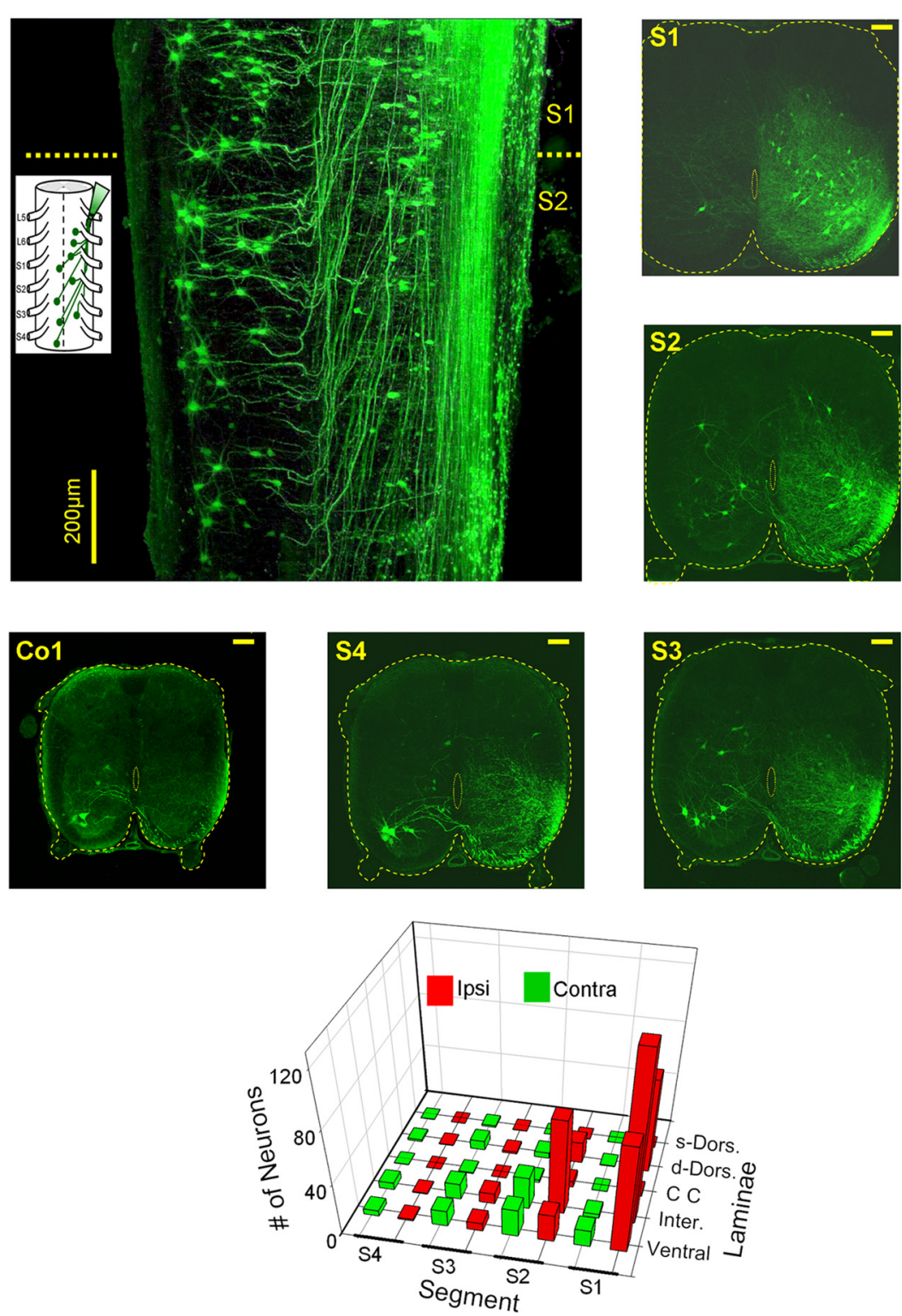

Figure 7. Rostrally projecting VLF/LF neurons. Schematic ventral view of backfilling of cut VLF axon bundles with fluorescein dextran at the left lumbosacral junction is superimposed with a projected confocal image (40 of 65 optical slices, $8 \mu \mathrm{m}$ each) of sacral neurons labeled through the cut VLF axons at the left lumbosacral junction in a whole mount transparent preparation of the spinal cord. Projected confocal images of 70- $\mu \mathrm{m}$-thick cross sections through the S1, S2, S3, S4 and C01 in one of the five labeling experiments performed in this series are shown to the right and below the image of the whole mount preparation. Calibration bars: $100 \mu \mathrm{m}$. The 3D histogram below shows the segmental and laminar distribution of the labeled VLF neurons. The numbers of neurons are means of five labeling experiments. For abbreviations, see Fig. $6 \mathrm{~A}$.

decreased, and the proportion of the contralateral labeled neurons increased with distance from the fill. In this way, most of the VLF/LF neurons in S3, S4, and Co1 were located contralateral to the fill (Fig. 7, cross sections S3, S4, Co1). Moreover, it should be noted that the axons of the contralaterally labeled VLF/LF neurons crossed the sacral cord through the ventral commissure and ascended rostrally for up to 2 segments within the VF before joining the VLF (Fig. 7, whole mount and cross sections). This finding suggests that some of these crossed axons are interrupted following VF cuts, but are spared after VLF lesions.

The laminar distribution of the labeled VLF/LF neurons (Fig. 7, bottom) was similar to that of the VF neurons (shown in Fig. $6 \mathrm{~A}$ ). Most of the neurons were distributed within the deep dorsal 


\section{DLF Fill at S1}
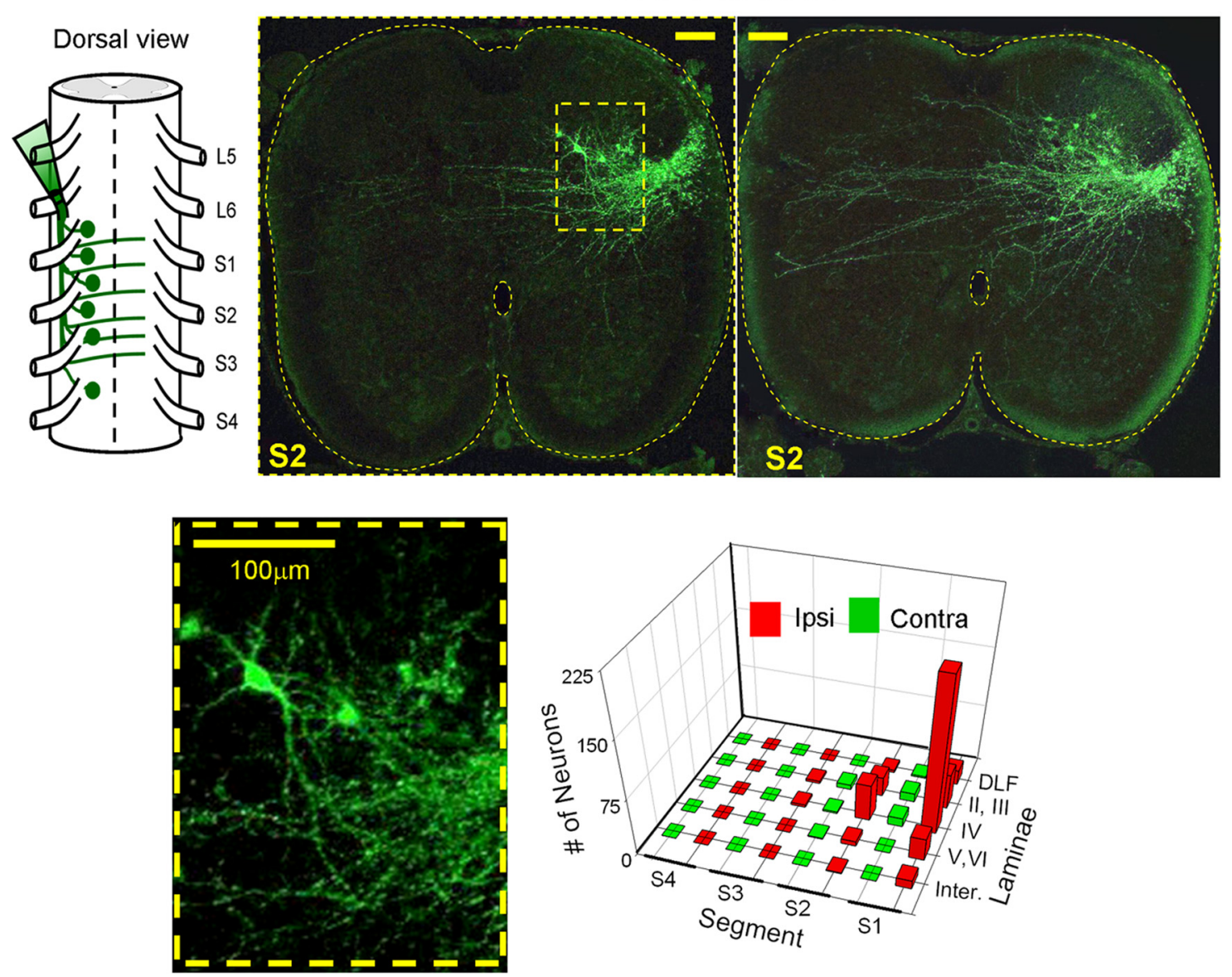

Figure 8. Retrograde labeling of DLF neurons. Schematic dorsal view of retrograde labeling of Cut DLF axon bundles at the rostral S1 level are superimposed with the rostral face of a projected confocal image of a cross section cut through the $\$ 2$ segment (the image consists of $2 / 8,8 \mu \mathrm{m}$ optical slices). The rectangular region delineated by dashed line in the upper cross sections is enlarged on the lower left panel to show more details of some of the labeled neurons. The 3D histogram on the lower right shows the segmental and laminar distribution of the labeled DLF neurons. The numbers of neurons are means of 11 labeling experiments. Calibration bars, $100 \mu \mathrm{m}$.

horn and laminae VII, VIII, IX and X. However, in contrast to the VF neurons some of the VLF/LF neurons were located in the more superficial dorsal horn layers, and more VLF/LF neurons were labeled in the S3 and S4 segments and Co1. This latter finding indicates that the VLF/LF neurons in the sacral cord have longer ascending projections than the VF neurons.

\section{DLF projections}

Retrograde labeling of cut DLF axons at the lumbosacral junction (Fig. 8) revealed fewer labeled neurons in the sacral segments of the cord. The vast majority of the neurons were found in S1 and S2 ipsilaterally to the fill. They had small somata and relatively un-branched dendritic trees. These DLF neurons were located only in the dorsal laminae of the gray matter and in the dorsolateral white matter (the latter is consistent with the lateral spinal nucleus of rodents (Gwyn and Waldron, 1968, 1969; Jiang et al., 1999; Olave and Maxwell, 2004; Dutton et al., 2006; Pinto et al., 2010). Few neurons were found in lamina VII. Interestingly, ascending and descending DLF axons crossed the midline through the dorsal gray matter and branched to terminate mainly at the contralateral gray (Fig. 8, right, top).

\section{Discussion}

Sensory input from load and joint receptors is a potent activator of the locomotor CPGs in spinal cord injury patients (for review, see Dietz, 2009). Therefore, it is crucially important to under- stand the functional organization and mechanisms of action of the pathways involved in sensory activation of the CPGs and examine their capacity to activate the pattern generating circuitry when the white matter tracts are damaged due to traumatic injury to the spinal cord. In the present study we show that stimulation of sacrocaudal afferents can effectively produce the locomotor rhythm in the isolated spinal cord of the neonatal rat when the continuity of the white matter tracts is severely damaged, and when the direct connectivity between sacral neurons with long ascending projections and the CPGs is interrupted. We also showed that the generation of the rhythm by SCA stimulation depends on synaptic activation of segmental and nonsegmental sacral relay neurons (Figs. 2-4, 9) whose crossed and uncrossed projections travel rostrally through the entire ventral and lateral spinal white matter (i.e., VF, VLF/LF, and DLF). However, despite the fact that specific lesions of any of the known divisions of the white matter did not block the rhythm produced by SCA stimulation, these lesions had differential effects on the rhythm. Lesions of the VF increased the frequency of the rhythm, prevented the decay in frequency during the stimulus train and decreased the power of the rhythm (Fig. 3). Lesions of the DLF decreased the mean frequency of the rhythm during the stimulus train, but did not affect the mean power (Fig. 3 ). Because changes in the frequency of the rhythm indicate effects on the pattern generating circuitry, it is suggested that the VF and DLF lesions affected the pattern generating circuitry in different 
ways and that the pathways projecting through these funiculi to the CPGs may subserve different functions. The DF and VLF/LF lesions had no significant effects on the rhythm; however it was possible to produce the rhythm when the VLF was spared as the only intact funiculi but not when the DF was left the only bilaterally intact funiculi (Figs. 2, 3; only VLF/LF intact and only DLF intact). Thus, these results reveal the presence of a versatile projection system that exerts funicularspecific effects on the rhythm, as well as the capacity to generate the rhythm by a specific funiculus (pathways projecting via the VF, and to a lesser extent via the DLF or the VLF/LF) when the rest of the funiculi are impaired (Fig. 9).

This multifunicular projection pattern of the sacral neurons activated by SCA stimulation to the CPGs differs from the bulbospinal projections to the cat locomotor CPGs, in which the VLF has been assumed to play a predominant role (Eidelberg et al., 1980; Jordan, 1991, 1998). In fact, our findings resemble more recent work showing the involvement of multifunicular descending projections in the control of overground locomotion (Brustein and Rossignol, 1998; Vilensky et al., 1992; Schucht et al., 2002; Loy et al., 2002a,b), and those reported for the bulbospinal pathways in the adult rat (Reed et al., 2006, 2009). However, it is important to emphasize that the role of the VLF may have been underestimated in the present work, because some of the crossed VLF axons entered the VLF after traveling through the sacral VF (Fig. 7) and were probably interrupted by VF cuts but spared after the VLF/LF lesions.

Another major finding of the present study that has been briefly mentioned above, concerns the mode of activation of the CPGs by the sacral relay neurons. The drive required for the activation of the hindlimb CPGs can be provided either by tract neurons with spinal collaterals or by propriospinal neurons with direct or indirect axonal projections to the CPGs. Ascending pathways that may play this role are the spinothalamic, spinoreticular and ventral spinocerebellar tracts (Trevino et al., 1972; Fields et al., 1975; Arsénio Nunes and Sotelo, 1985; Xu and Grant, 1990, 2005; Yamada et al., 1991). Some of these pathways have been reported to send spinal collaterals to different levels of the spinal cord and thereby may potentially contribute to activation of the CPGs by SCA stimulation (see Baldissera et al., 1981). Moreover, a number of long ascending pathways have also been described in cats (Molenaar and Kuypers, 1978; English et al., 1985; Krutki et al., 1997; Grottel et al., 1998) and rats (Matsushita, 1998; Dutton et al., 2006). These latter pathways have been suggested to contribute to coordination between the sacral lumbar and cervical segments of the spinal cord (Dutton et al., 2006). In the present study, we demonstrated that the hindlimb rhythm could be generated by SCA stimulation when the synaptic transmission of the spinal segments between S2 to L2 was blocked in the presence of low $\mathrm{Ca}^{+2} / \mathrm{High} \mathrm{Mg}^{+2} \mathrm{ASCF}, \mathrm{CNQX}, \mathrm{APV}$ and Atropine (Fig. $5 A$ ). Thus, the rhythm could be initiated by long ascending projections of the sacral neurons activated by SCA stimulation. However, we also showed that it was possible to produce the rhythm when the direct connectivity between the sacral and lumbar cord was interrupted at several loci (Fig. 5B). Thus, serial recruitment of propriospinal neurons with shortrange multifunicular projections has a significant contribution to the capacity of SCA stimulation to activate the hindlimb CPGs. This latter suggestion implies that many of the short ascending sacral neurons labeled by funicular back-filling at the mid-sacral level (Fig. 6B) may actually contribute to activation of the CPGs by SCA stimulation. Our suggestion that short projecting propriospinal neurons have a major role in sensory activation of the 
CPGs resembles recent reports demonstrating the involvement of short projecting propriospinal neurons in the descending control of the pattern generating circuitry (Cowley et al., 2008), their role as alternative communication pathways following traumatic spinal cord injuries (Guevremont et al., 2006; Courtine et al., 2008) and their potential involvement in functional recovery from spinal cord injuries (Yakovenko et al., 2007; Edgerton and Roy, 2009) and in developing neural repair strategies such as microstimulation of selected regions of the spinal cord (for review, see Bizzi et al., 2008).

In summary, our findings revealed that the SCA activation of the hindlimb rhythmogenic network is not mediated by a specific pathway. Rather, it involves several neural pathways which may act individually or as a group to initiate the rhythm. The mediating circuitry can be activated by perineal stimulation (Pearson and Rossignol, 1991), and by mechanical (Blivis et al., 2007) or irradiant heat stimulation of sacrocaudal dermatomes (Blivis et al., 2007; Mandadi et al., 2009), and by low- and high-intensity electrical stimulation of SCAs (Delvolvé et al., 2001; Blivis et al., 2007). Thus, the rhythm can be produced by activation of different sensory modalities and the nociceptive and nonnociceptive afferent pathways associated with them (Blivis et al., 2007; Mandadi et al., 2009). The sacral neurons activated by this multimodal system are distributed in different regions of the gray and white matter (Figs. 6-8). The neurons projecting through the VF and VLF/LF reside in the deep-dorsal, intermediate, and ventral laminae of the gray matter, while those projecting via the DLF are localized to the dorsal laminae of the gray matter and the dorsolateral white matter. Moreover, the axonal projections of these pathways are crossed and uncrossed, and can be activated separately (Strauss and Lev-Tov, 2003) or concurrently to produce the rhythm.

In addition, as already discussed, the rhythm could be produced by SCA stimulation when the continuity of long ascending projections of propriospinal and tract neurons was interrupted at different loci along the sacral cord, by serial activation of proprioneurons with short range multifunicular projections. However, the rhythm could also be generated when synaptic transmission of short projecting proprioneurons was blocked between rostral S2 to caudal L2 in the presence of low-calcium high-magnesium ACSF, CNQX and APV and Atropine. These long projections may allow us to identify their synaptic targets within the anterior lumbar segments and to establish how activation of these relay neurons can activate the rhythm. We are currently pursuing this approach by studying the properties of subpopulations of sacral neurons activated on SCA stimulation, the nature of their synaptic contacts with SCAs and their activity patterns during SCA stimulation (see Blivis et al., 2009).

In summary, the SCA pathways we have described in the neonatal cord exhibit substantial versatility, a high level of redundancy and an extreme resistance to damage of the white and gray matter of the spinal cord. Further studies are required to assess whether this protean and diverse sensory system is meaningful under physiological and pathophysiological conditions and whether its versatility can be used to reactivate the central pattern generators following traumatic spinal cord injuries.

\section{References}

Arsénio Nunes ML, Sotelo C (1985) Development of the spinocerebellar system in the postnatal rat. J Comp Neurol 237:291-306.

Baldissera F, Hultborn H, Illert M (1981) Integration in spinal neuronal systems. In: Handbook of Physiology (Brooks VB, ed), pp 509-595. Bethesda, MD: American Physiological Society.
Bizzi E, Cheung VC, d'Avella A, Saltiel P, Tresch M (2008) Combining modules for movement. Brain Res Rev 57:125-133.

Blivis D, Mentis GZ, O’Donovan MJ, Lev-Tov A (2007) Differential effects of opioids on sacrocaudal afferent pathways and central pattern generators in the neonatal rat spinal cord. J Neurophysiol 97:2875-2886.

Blivis D, Mentis GZ, O’Donovan MJ, Lev-Tov A (2009) Studies of sacral neurons involved in activation of the lumbar central pattern generator for locomotion in the neonatal rodent spinal cord. Soc Neurosci Abstr 35:564.8.

Brustein E, Rossignol S (1998) Recovery of locomotion after ventral and ventrolateral spinal lesions in the cat. I. Deficits and adaptive mechanisms. J Neurophysiol 80:1245-1267.

Colombo G, Wirz M, Dietz V (2001) Driven gait orthosis for improvement of locomotor training in paraplegic patients. Spinal Cord 39:252-255.

Courtine G, Song B, Roy RR, Zhong H, Herrmann JE, Ao Y, Qi J, Edgerton VR, Sofroniew MV (2008) Recovery of supraspinal control of stepping via indirect propriospinal relay connections after spinal cord injury. Nat Med 14:69-74.

Cowley KC, Zaporozhets E, Schmidt BJ (2008) Propriospinal neurons are sufficient for bulbospinal transmission of the locomotor command signal in the neonatal rat spinal cord. J Physiol 586:1623-1635.

Delvolvé I, Gabbay H, Lev-Tov A (2001) The motor output and behavior produced by rhythmogenic sacrocaudal networks in spinal cords of neonatal rats. J Neurophysiol 85:2100-2110.

Dietz V (2009) Body weight supported gait training: from laboratory to clinical setting. Brain Res Bull 78:I-VI.

Dietz V, Harkema SJ (2004) Locomotor activity in spinal cord-injured persons. J Appl Physiol 96:1954-1960.

Dietz V, Müller R, Colombo G (2002) Locomotor activity in spinal man: significance of afferent input from joint and load receptors. Brain 125:2626-2634.

Dodt HU, Leischner U, Schierloh A, Jährling N, Mauch CP, Deininger K, Deussing JM, Eder M, Zieglgänsberger W, Becker K (2007) Ultramicroscopy: three-dimensional visualization of neuronal networks in the whole mouse brain. Nat Methods 4:331-336.

Dutton RC, Carstens MI, Antognini JF, Carstens E (2006) Long ascending propriospinal projections from lumbosacral to upper cervical spinal cord in the rat. Brain Res 1119:76-85.

Edgerton VR, Roy RR (2009) Activity-dependent plasticity of spinal locomotion: implications for sensory processing. Exerc Sport Sci Rev 37:171-178.

Edgerton VR, Courtine G, Gerasimenko YP, Lavrov I, Ichiyama RM, Fong AJ, Cai LL, Otoshi CK, Tillakaratne NJ, Burdick JW, Roy RR (2008) Training locomotor networks. Brain Res Rev 57:241-254.

Eidelberg E, Story JL, Meyer BL, Nystel J (1980) Stepping by chronic spinal cats. Exp Brain Res 40:241-246.

English AW, Tigges J, Lennard PR (1985) Anatomical organization of long ascending propriospinal neurons in the cat spinal cord. J Comp Neurol 240:349-358.

Etlin A, Blivis D, Ben-Zwi M, Lev-Tov A (2009) Proprioneurons with multifunicular projections are activated by sacrocaudal afferents to turn on the pattern generating circuitry in the absence of supraspinal control. Soc Neurosci Abstr 35:564.7.

Fields HL, Wagner GM, Anderson SD (1975) Some properties of spinal neurons projecting to the medial brain-stem reticular formation. Exp Neurol 47:118-134.

Gabbay H, Lev-Tov A (2004) Alpha-1 adrenoceptor agonists generate a "fast" NMDA receptor-independent motor rhythm in the neonatal rat spinal cord. J Neurophysiol 92:997-1010.

Gabbay H, Delvolvé I, Lev-Tov A (2002) Pattern generation in caudallumbar and sacrococcygeal segments of the neonatal rat spinal cord. J Neurophysiol 88:732-739.

Grottel K, Krutki P, Mrówczyński W (1998) Triple projections of neurones located in S1 and S2 segments of the cat spinal cord to the C6 segment, the cerebellum and the reticular formation. Exp Physiol 83:737-746.

Guevremont L, Renzi CG, Norton JA, Kowalczewski J, Saigal R, Mushahwar VK (2006) Locomotor-related networks in the lumbosacral enlargement of the adult spinal cat: activation through intraspinal microstimulation. IEEE Trans Neural Syst Rehabil Eng 14:266-272.

Gwyn DG, Waldron HA (1968) A nucleus in the dorsolateral funiculus of the spinal cord of the rat. Brain Res 10:342-351.

Gwyn DG, Waldron HA (1969) Observations on the morphology of a nu- 
cleus in the dorsolateral funiculus of the spinal cord of the guinea-pig, rabbit, ferret and cat. J Comp Neurol 136:233-236.

Jiang MC, Liu L, Gebhart GF (1999) Cellular properties of lateral spinal nucleus neurons in the rat L6-S1 spinal cord. J Neurophysiol 81: 3078-3086.

Jordan LM (1991) Brainstem and spinal cord mechanisms for the initiation of locomotion. In: Neurobiological basis of human locomotion (Shimamura M, Grillner S, Edgerton VR, eds), pp 3-20. Tokyo: Japan Scientific Series.

Jordan LM (1998) Initiation of locomotion in mammals. Ann N Y Acad Sci 860:83-93.

Kremer E, Lev-Tov A (1997) Localization of the spinal network associated with generation of hindlimb locomotion in the neonatal rat and organization of its transverse coupling system. J Neurophysiol 77:1155-1170.

Krutki P, Mrówczynski W, Grottel K (1997) Lamina VII and VIII neurons of the S2 segment bilaterally projecting to the C6 segment of the spinal cord in the cat. J Physiol Paris 91:325-330.

Lavrov I, Courtine G, Dy CJ, van den Brand R, Fong AJ, Gerasimenko Y, Zhong H, Roy RR, Edgerton VR (2008) Facilitation of stepping with epidural stimulation in spinal rats: role of sensory input. J Neurosci 28:7774-7780.

Lev-Tov A, Delvolvé I (2000) Pattern generation in non-limb moving segments of the mammalian spinal cord. Brain Res Bull 53:671-675.

Lev-Tov A, O’Donovan MJ (2009) Spinal cord: neonatal circuits. In: Encyclopedia of neuroscience (Squire LR, ed). Oxford: Academic.

Lev-Tov A, Delvolvé I, Kremer E (2000) Sacrocaudal afferents induce rhythmic efferent bursting in isolated spinal cords of neonatal rats. J Neurophysiol 83:888-894.

Lev-Tov A, Etlin A, Blivis D (2010) Sensory induced activation of pattern generators in the absence of supraspinal control. Ann N Y Acad Sci 1198:54-62.

Loy DN, Magnuson DS, Zhang YP, Onifer SM, Mills MD, Cao QL, Darnall JB, Fajardo LC, Burke DA, Whittemore SR (2002a) Functional redundancy of ventral spinal locomotor pathways. J Neurosci 22:315-323.

Loy DN, Talbott JF, Onifer SM, Mills MD, Burke DA, Dennison JB, Fajardo LC, Magnuson DS, Whittemore SR (2002b) Both dorsal and ventral spinal cord pathways contribute to overground locomotion in the adult rat. Exp Neurol 177:575-580.

Mandadi S, Nakanishi ST, Takashima Y, Dhaka A, Patapoutian A, McKemy DD, Whelan PJ (2009) Locomotor networks are targets of modulation by sensory transient receptor potential vanilloid 1 and transient receptor potential melastatin 8 channels. Neuroscience 162:1377-1397.

Matsushita M (1998) Ascending propriospinal afferents to area X (substantia grisea centralis) of the spinal cord in the rat. Exp Brain Res 119:356-366.

Molenaar I, Kuypers HG (1978) Cells of origin of propriospinal fibers and of fibers ascending to supraspinal levels. A HRP study in cat and rhesus monkey. Brain Res 152:429-450.

Mor Y, Lev-Tov A (2007) Analysis of rhythmic patterns produced by spinal neural networks. J Neurophysiol 98:2807-2817.

Mor Y, Lev-Tov A (2008) The use of GPU (graphic processing unit)-based parallel computing to determine higher-order correlation between signals produced by spinal neuronal networks. Israel Society for Neuroscience Conference, Eilat, Israel, Dec 7-9, 2008.

Mor Y, Lev-Tov A (2009) Evolutionary bi-coherence analysis of higher or- der interaction between different frequency bands of rhythmic signals produced by spinal neuronal networks. J Mol Neurosci 39 [Suppl 1]:s132.

Olave MJ, Maxwell DJ (2004) Axon terminals possessing alpha2Cadrenergic receptors densely innervate neurons in the rat lateral spinal nucleus which respond to noxious stimulation. Neuroscience 126:391403.

Pearson KG (2004) Generating the walking gait: role of sensory feedback. Prog Brain Res 143:123-129.

Pearson KG, Rossignol S (1991) Fictive motor patterns in chronic spinal cats. J Neurophysiol 66:1874-1887.

Pinto V, Szucs P, Lima D, Safronov BV (2010) Multisegmental $A_{\delta^{-}}$and $\mathrm{C}$-fiber input to neurons in lamina I and the lateral spinal nucleus. J Neurosci 30:2384-2395.

Reed WR, Shum-Siu A, Onifer SM, Magnuson DS (2006) Inter-enlargement pathways in the ventrolateral funiculus of the adult rat spinal cord. Neuroscience 142:1195-1207.

Reed WR, Shum-Siu A, Whelan A, Onifer SM, Magnuson DS (2009) Anterograde labeling of ventrolateral funiculus pathways with spinal enlargement connections in the adult rat spinal cord. Brain Res 1302:76-84.

Rossignol S, Dubuc R, Gossard JP (2006) Dynamic sensorimotor interactions in locomotion. Physiol Rev 86:89-154.

Schucht P, Raineteau O, Schwab ME, Fouad K (2002) Anatomical correlates of locomotor recovery following dorsal and ventral lesions of the rat spinal cord. Exp Neurol 176:143-153.

Strauss I, Lev-Tov A (2003) Neural pathways between sacrocaudal afferents and lumbar pattern generators in neonatal rats. J Neurophysiol 89:773-784.

Torrence C, Compo GP (1998) A practical guide to wavelet analysis. Bull Am Meteorol Soc 79:61-78.

Trevino DL, Maunz RA, Bryan RN, Willis WD (1972) Location of cells of origin of the spinothalamic tract in the lumbar enlargement of cat. Exp Neurol 34:64-77.

Vilensky JA, Moore AM, Eidelberg E, Walden JG (1992) Recovery of locomotion in monkeys with spinal cord lesions. J Mot Behav 24:288-296.

Wernig A, Müller S, Nanassy A, Cagol E (1995) Laufband therapy based on 'rules of spinal locomotion' is effective in spinal cord injured persons. Eur J Neurosci 7:823-829.

Whelan P, Bonnot A, O'Donovan MJ (2000) Properties of rhythmic activity generated by the isolated spinal cord of the neonatal mouse. J Neurophysiol 84:2821-2833.

Xu Q, Grant G (1990) The projection of spinocerebellar neurons from the sacrococcygeal region of the spinal cord in the cat. An experimental study using anterograde transport of WGA-HRP and degeneration. Arch Ital Biol 128:209-228.

Xu Q, Grant G (2005) Course of spinocerebellar axons in the ventral and lateral funiculi of the spinal cord with projections to the posterior cerebellar termination area: an experimental anatomical study in the cat, using a retrograde tracing technique. Exp Brain Res 162:250-256.

Yakovenko S, Kowalczewski J, Prochazka A (2007) Intraspinal stimulation caudal to spinal cord transections in rats. Testing the propriospinal hypothesis. J Neurophysiol 97:2570-2574.

Yamada J, Shirao K, Kitamura T, Sato H (1991) Trajectory of spinocerebellar fibers passing through the inferior and superior cerebellar peduncles in the rat spinal cord: a study using horseradish peroxidase with pedunculotomy. J Comp Neurol 304:147-160.

Zar JH (1999) Biostatistical analysis. Upper Saddle River, NJ: Prentice Hall. 